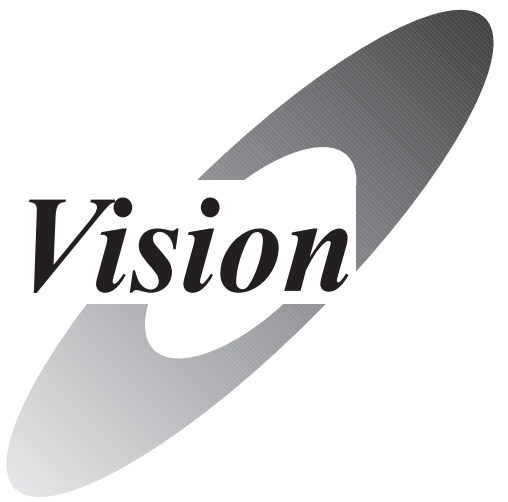

\title{
Current Status and Issues for Development of Solid Oxide Fuel Cells
}

\author{
Koichi EGUCHI
}

Solid oxide fuel cells (SOFCs) have been attracting attention as new power generating systems because of their advantageous features such as high conversion efficiency for co-generation and hybrid generation systems, multi-fuel capability, and absence of precious metal components. High temperature operation of the system, however, accompanied several difficulties in materials design, such as thermal degradation, oxidation-reduction resistance, microstructural modification, and solid state reaction between components. These difficulties impeded the development of the systems. However, current research and development SOFCs approached closely to the commercialization stage. The SOFC systems of 1-50 kWe-classes for the co-generation purpose have been successfully operated by several Japanese companies as several projects and have realized high generation efficiencies exceeding $40 \%$.

High operating temperature of SOFCs allows to combine with gas turbines to attain highest efficiency among the generation systems based on fossil fuels. This hybrid system of SOFC with micro-gas turbine has been developed; i.e., a $200 \mathrm{kWe}$-class system using the tubular cells stacks has achieved the electrical efficiency of $52 \%$ LHV. These achievements encouraged development of SOFCs toward the commercialization.

The special issue of SOFC should be timely as the research and development of SOFCs has stepped into the new phase. Continuous R\&D effort should be devoted to realization of cogeneration systems and hybrid systems. However the commercialization will be possible only after establishment of reliability of SOFC system. For example, the target degradation rate for the SOFC units in several projects, being set less than $0.25 \% / 1000 \mathrm{~h}$, was often difficult to achieve. Number of factors have been pointed out, but most of them are related with the degradation of component materials. For minimization of the degradation rate, the cell and stack component will be analyzed from various aspects.

Reduced temperature operation of SOFC is considered to open new application fields not only in stationary applications, but also in portable and mobile applications. Micro-tubular cells have been developed for a ceramic micro-reactor. Quicker start-up and shut-down is attractive for small scale generators with large load variations. Thermal degradation due to thermal expansion mismatch, solid stare reaction between components, and sintering are expected to be mitigated by operating the cells at $700-800{ }^{\circ} \mathrm{C}$. It is noted also that the reduced temperature operation enables us to use metallic components or glass-based sealants. As a substitute for yttria-stabilized zirconia (YSZ), new ion conductive oxides have been employed in SOFC systems.

Unlike other type of fuel cells operative at low temperatures, hydrocarbon fuels are suitable for SOFCs as they can be directly supplied to the cell unit in internal reforming mode of operation. The fuel processing system can be simplified in principle because of the high temperature for conversion of fuels. The integrated coal gasification fuel cell combined cycle (IGFC) has been considered as the final goal of large SOFC systems. The capability of generation with various fuels could be possible after clarification of reforming behavior, deterioration with fuel impurities, and carbon deposition.

As mentioned, the materials and electrochemical reactions have been continuously the main issues for the development of SOFCs, e.g., deterioration of components via solid state reactions, sintering of component, high temperature degradation with vapor, new electrode materials, and stability of metallic and ceramic interconnects, electrolyte materials fabrication procedures, and basic electrochemical reaction at the triple phase boundary. Numbers of new materials have been discovered or proposed from these basic researches on solid electrochemistry. Some of these subjects have been also discussed in this special issue on solid oxide fuel cells.

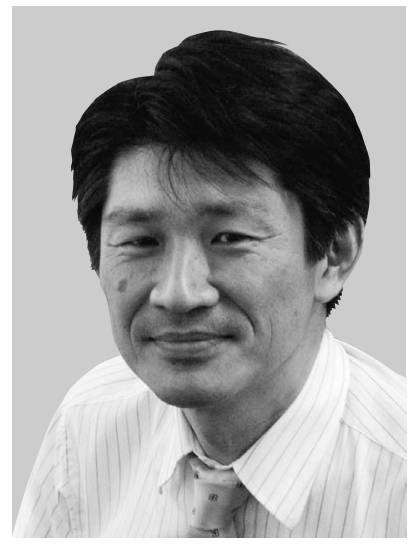

Koichi EGUCHI Professor, Graduate School of Engineering, Kyoto University 